\title{
Health Service Delivery and Utilization in Timor-Leste: A Qualitative Study ${ }^{1}$
}

May 8, 2005

\footnotetext{
${ }^{1}$ This report was undertaken as part of a broader Health Sector Review in Timor-Leste that is currently being undertaken by the World Bank. It was prepared by Alexander Edmonds (Department of Anthropology, Macquarie University), in collaboration with Rui Paulo de Jesus, Magnus Lindelow, and Ian Morris from the World Bank. Research assistance was provided by Lizety Mendonça and Aguido da Silva. The findings, interpretations, and conclusions expressed herein are those of the authors, and do not necessarily reflect the views of the International Bank for Reconstruction and Development, the World Bank and its affiliated organizations, or those of the Executive Directors of the World Bank or the governments they represent. The authors would like to thank the health care workers and clients for their thoughtful contributions and generous donation of time to this research. The team gratefully acknowledges the generous support of the Government of the Netherlands through the Bank-Netherlands Partnership Program.
} 


\section{Table of Contents}

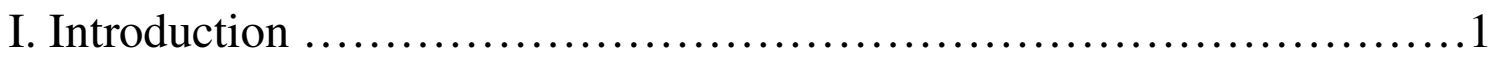

II. Findings

Part 1: Health seeking behaviour and barriers to the utilization of health services ...................................................4

Part 2: Problems in service delivery and human resource issues .....18

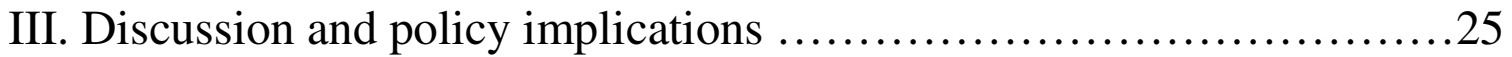

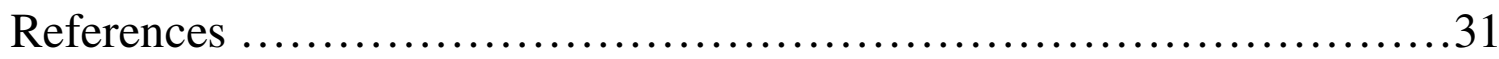

Appendix I: Methodology ...........................................34

Appendix II: Matan dook treatments ............................,.....36 


\section{Introduction}

Since independence, the health sector in Timor-Leste has achieved considerable progress in re-establishing provision of basic services and rebuilding facilities destroyed in the post-referendum violence. Timor-Leste, however, continues to struggle with a high burden of disease. Poor health is related to some factors present in many developing countries: environmental sanitation, poverty, food security, a shortage of doctors, and the difficulty of reaching some rural communities. Some problems are more specific to Timor-Leste: violence during the Indonesian occupation, the destruction of the health care sector, and a situation of "medical pluralism" in which long established practices of home care and treatment by traditional healers co-exist with recently introduced biomedical services. Furthermore it is worth keeping in mind that a comprehensive system of primary care was only established relatively recently, in the late 1970s, by an occupying power. Another challenge the health sector faces is client low utilization of health services. The 2003 Demographic and Health Survey (DHS) reports that about a fifth of poor households have never used the health care facility closest to their house. While it is clear that many households are unwilling or unable to access health care, the reasons for these barriers are poorly understood. One aim of this report is to help fill this gap in knowledge by providing contextual information on health seeking behaviour.

A second aim is to shed light on human resource challenges in the health sector. In recent years, there has been broad agreement that human resources have been a neglected aspect of health system development in the developing world (Mills et al 2002). In many countries, larger private sectors have contributed to out migration, an erosion of public service mentality, and practices such as informal charging. There has also been a growing acknowledgment of the power of the health worker to affect health outcomes (Chen et al 2004). Policy makers have recognized that health workers are active agents, responding to changes in labour markets and health crises (Lindelow et al 2004). This report is intended to contribute to an understanding of health worker concerns and performance problems in Timor-Leste based on group discussions with nurses and midwives.

Research addressed the following two themes, in both the public and private sectors:

- Health care seeking behaviour and especially the determinants of low levels of utilization of health care.

- Human resource issues, including factors affecting health workers' job motivation, satisfaction, and performance.

Each of these themes was explored in both rural and urban regions. Research participants and research sites were selected in order to obtain comparative information on government and NGO providers in both urban and rural areas. NGO providers included the two largest in the country: the Cooperativo Café Timor and the network of Catholic clinics. Methodology consisted of focus groups and semi- 
structured interviews designed to elicit detailed, contextual information that cannot be collected as part of large, representative studies (see appendix for more information).

As part of the first phase of the Health Sector Review undertaken by the $\mathrm{MoH}$ and the World Bank, the research addresses several areas of policy relevance: causes of service delivery problems, community perceptions of health care providers, human resource challenges, access to health care in urban and rural areas, and the capacity of the private sector to support health objectives.

\section{Findings}

This section has two parts. In the first part, the report discusses barriers to the utilization of health services. It also analyses client health seeking behaviour and factors that influence choice of provider. The second part discusses problems in service delivery and human resource issues, drawing primarily on the perspectives of health care workers.

\section{Part 1: Health seeking behaviour and barriers to the utilization of health services}

To understand barriers to health care, it is necessary to look first at how illness is diagnosed and perceived by clients. Health workers and clients do not of course classify serious illness or health risks in the same way. As many studies in medical anthropology have shown, systems of ethnomedicine are highly variable and deeply embedded in cultural notions of cosmology, ecology, death, personhood, sexuality, etc. (Chapman 2003, Scheper-Hugues 1992, Kleinman et al 1978). Furthermore, folk diagnosis and treatments of illness persist long after contact with biomedicine (Jefferds 2002). In the case of Timor-Leste, it should be emphasized that a comprehensive health care system was introduced only in the last 30 years, and under inauspicious historical circumstances. While it is beyond the scope of this study to provide a detailed description of traditional concepts of illness and healing in Timor-Leste, a few points affecting health care utilization are worth mentioning.

Research suggested that clients make health care decisions within a context of

medical pluralism. As is the case with many syncretistic religions, faith in the dominant explanatory model and practice does not preclude continued adherence to tradition. Client attitudes suggested openness to applying different diagnostic criteria and treatments, even when their underlying principles seem to be contradictory. Rather than a simple opposition between biomedicine and ethnomedicine then folk perceptions of biomedical disease aetiology co-exist and combine with various forms of traditional knowledge. These "syncretic models" often deviate significantly from the biomedical models that clinicians and health promoters intend to transmit, and can affect health outcomes (Muela et al 2002).

\section{Ethnomedicine and perceptions of disease aetiologies}

Many clients distinguish physical and "non-physical" causes of disease. Physical vectors -- knowledge of which is garnered from contact with health workers and health promotion materials -- include mosquitos, garbage, dirt, and the rainy season. But clients 
also mention other causes of illness: violations against the sacred house; neglect of ritual duties towards the dead; black magic motivated by jealousy; and malevolent spirits. ${ }^{2}$ The cause of a particular illness is sometimes decided retroactively, according to the effectiveness of treatment. For example, an illness that does not respond to "foreign medicine" (aimoruk malai) may indicate an underlying magical aetiology. A traditional healer (matan dook) explained how he divined the cause of fever:

I can tell when a person gets sick by chewing betel-nut and using candle light ... If a doctor can not cure a fever it means that it was caused by either black magic or not following the rules of the sacred house. (Matan dook)

We can not just sit at home 'marinating' [i.e. as victims of black magic]. If the doctor can't help, it doesn't mean he's not good, but we'll have to find people who know Timorese medicine to help. (Matan dook client)

Another distinction sometimes made is between "outside" and "inside" (moras husi laran) disease, with the latter requiring "foreign medicine."

Diseases that come from the inside require a visit to the clinic, because they don't get better quick enough with herbal medicine. (Rural client)

However, herbal medicines may be used both topically and internally and matan dook do not generally limit their field of expertise to the treatment of wounds or skin ailments. Group discussions did not explicitly address the complex issue of mental health. Some clients did cite mental illness though as an example of a kind of disease that can not be cured by "foreign medicine."

If you have an internal infection then you need to get hospital treatment. But if you have mental illness you can get medicine from the hospital but it will only calm it down, not cure it. Eventually you'll need traditional medicine to be cured. (Rural client)

Perceptions of illness aetiology are thus important because they influence the type of treatment sought.

Blood, which is classified into various good and harmful forms, also figures centrally in community knowledge and practice. Red blood (raan mean) is healthy blood, while white blood (raan mutin), black blood (raan metan), and dirty blood (raan foer) are associated with various health problems and require preventative and curative measures. For example, black or dirty blood in postpartum women must be expelled by heating the body -through drinking hot fluids and the practice of "sitting fire" (tuur ahi). Black blood can also be caused by head traumas or surgery. "White blood going to the head" is considered to be a serious health threat to postpartum women. This condition is triggered by contact with cold air or water and can cause pallor, dizziness, or even madness and death (Van Schoor 2003). Van Schoor suggests that the symptoms of a "white blood" infection resemble puerperal psychosis linked to genital sepsis. Regardless

\footnotetext{
${ }^{2}$ For example, a broken bone was caused by the spirit of a boy's grandfather, which had become displeased by failure to follow the practice of giving an infant the nickname of a recently deceased grandparent.
} 
though of whether local disorders have a biomedical equivalent, they are important for understanding health seeking behaviour, and may profitably be addressed by education and health promotion efforts.

\section{Perceptions and misunderstandings of biomedicine}

Attitudes towards biomedicine or "foreign medicine" (aimoruk malai) are generally positive. However, it is worth pointing out that even where biomedical illness terms have been adopted, clients may underestimate the health threat. Malaria, for example, is often classified as a "normal" rather than as a serious illness. This informal rating of illness severity may lead patients to delay or forego medical treatment.

My parents are not educated and so when there is fever or another illness in the family they think it is nothing. I might think it's better to go to the hospital, but the will say it's better to use traditional [i.e. herbal] medicine. (Urban client)

Folk perceptions of "foreign medicine" also have implications for pharmaceutical demand and compliance issues. Clients rate pharmaceuticals according to the form in which they are administered and their "strength." For example, due to a belief that injections (sona) are more powerful than orally administered medicine, nurses may be pressured for inappropriate injections (there was also a report from an expatriate doctor needles being reused in some regions). Availability of sona may also affect provider choice.

Sometimes if we go to a clinic they just give us medicines, and some clinics give both injections and medicines. In this case we prefer go to the one that can give us both injection and medicines. (Urban client)

In my CHC they don't give any injection, they just give medicines, and the medicines sometimes cannot cure the disease. I think if it's fever they must give an injection to the patient. (Urban client)

On the other hand, perceptions of certain pharmaceuticals as being too "strong" may also affect health seeking behaviour. A belief that an injection can kill a patient, especially a child, with a high fever can lead to delays in or avoidance of treatment. (This belief may be traceable to fever associated with vaccines.)

If a kid with a high fever is taken to the hospital the nurse will give him an injection. But many people believe that if you have a fever you can die from an injection [because it is too strong] and so they are afraid to take their kids to the hospital when they have a fever. (Urban client)

Another possible health implication is that pharmaceuticals not perceived as "powerful" will be rejected, or that resources will be wasted on buying patent forms of pharmaceuticals. For example, a pharmacist argued, "patent antibiotics are more powerful" than the generics available at government facilities: "Most people prefer to buy the patent one but this is only for people who have money." 


\section{The decision to seek health care in a context of medical pluralism}

How do folk disease aetiologies affect health seeking behaviour? Treatment options generally fall within four broad categories: self-treatment with traditional (herbal) medicine, self-treatment with pharmaceuticals, consultation with a traditional healer, and treatment by a biomedical provider. Complex factors affect which of these -- or which combination -- is chosen. Patients may consider past experiences with various providers, the familiarity and severity of the illness, and ease of access to clinics. In some cases, the perception of the cause of the illness will also affect the decision.

We believe that some illnesses require treatment by a traditional healer (matan dook), those illnesses that are caused by the sacred house (uma lulik). The matan dook can tell what is wrong by taking betel nuts.

In other words, disease aetiologies that fall outside the categories of biomedicine may require the intervention of a traditional healer.

At this point, it may be useful to point out that there are several types of traditional healers offering services in Timor-Leste. Note that most of these practitioners may also be referred to by the Indonesian term dukun.

Matan Dook (literally "eye far"): a kind of shaman, usually a man, who practices divination and performs various rites, which may involve animal sacrifice, candle smoke, and betel nut chewing. Some matan dook have national reputations and attract patients willing to spend considerable amounts of money on their services. One matan dook in Dili, for example, claimed to have a clientele that extended from Lospalos to Maliana, Portugal and Australia and to have cured 3000-4000 people between 1979 and 2005. Some matan dook incorporate aspects of Christian ritual into their practice, such as praying with rosary beads.

Tohar: a bone setter

Ema Aimoruk Timor: herbalist

Daya or Liman Badain ("hand workers") or simply Tia Ferik ("old aunt"): Birth attendants who administer massage to pregnant women and assist with deliveries and postpartum care. Some also use various herbal preparations. Some can use their hands to turn a baby in breech position or relieve pain during a miscarriage. They usually treat only local women (See Van Schoor 2003).

The category of "traditional healer" thus includes several types of practitioners who employ a range of practices, only some of which may be of potential concern to policy makers. Some herbal preparations of course have therapeutic benefits, though more research is needed on the pharmacological properties of plant-based medicines used in Timor-Leste. Other practices, such as the postpartum tuur ahi ("sitting fire"), may contribute to respiratory infections, for example. Even where practices cause no direct health problems it may be asked whether reliance on traditional healers leads some clients to delay or forego biomedical treatment. How do the various traditional healers affect health outcomes?

This report can not provide a comprehensive answer, but we can make a few points based on group discussions with clients. "Foreign" and "Timorese" medicine are seen as complementary. "When one fails, try the other" often seems to be the logic behind health seeking decisions. Traditional healers and birth attendants also appear to 
have a generally favourable view of biomedicine, and will in some cases encourage clients to seek care at CHCs or hospitals, though there is no organized system of referrals in place. Sequential treatment is common. Patients who cannot be cured at a clinic are commonly taken to a matan dook (and vice versa). Which option is chosen first, however, varies. In some cases, performing a ritual (adat) is a necessary preparation for a successful visit to a hospital or clinic.

Some women who are bleeding too much before the baby is born perform a ritual activity before they come to the hospital. So when they get to the hospital they are already unconscious. I am not sure why they do this but I guess this is their belief: if they don't do a ritual then they will not get cured when they go to the hospital. (Rural worker)

Reliance on traditional healers, however, also leads some clients to seek out biomedicine only for very advanced illnesses.

Some of them have been to a matan dook and perform a ritual for about a week or more, and if they don't get cured then they will come to the hospital. But some come here when death is a few hours away and we can not do anything. (Rural worker)

The treatment's failure in these instances will of course not add to confidence in "foreign medicine." Nurses complain of a kind of vicious circle whereby users do not have confidence in biomedicine and so delay seeking care, thereby prejudicing the success of the treatment. The patient will then be confirmed in her belief that the health worker is not skilled.

The problem is significant enough that some rural nurses advocate health promotion that addresses community reliance on traditional healers and birth attendants:

I think there must be a team to go to the community to explain to them how important it is to seek health care, because when they get sick they perform a ritual first before they come to the hospital and they think they get sick because they didn't perform a ritual activity. (Rural worker)

A lot of people here still perform ritual activity, or go to dukun when they get sick. Some even say, "If medicines can not cure you, and if you don't perform a ritual activity, then you just wait to die." So when some one says this, it will affect other people in their community psychologically. So they will start to give their cows to the matan dooks instead of selling the cows to get money for treatment food. (Rural worker)

Attitudes towards traditional healers varied considerably, apparently independently of indicators such as income, education, and gender. In some areas of the coffee-growing regions, according to nurse staff, there has been a decrease in visits to matan dook and TBAs. Some poor people, for example, avoided matan dook -- either because they couldn't afford them or because they didn't trust them. On the other hand, some middle class, urban residents are regular clients willing to spend considerable sums of money on cures. 
When my older sister was sick we took her to see all the doctors at the hospital but they all said the problem was blood pressure. We found then a matan dook in Maliana and witnessed the ritual he performed on my sister. When he finished, he charged $\$ 350$, and before we left he wanted us to pay the whole amount. Finally we gave him $\$ 300$ plus some animals and he promised to come back in two days. But he didn’t come back and my sister died soon after.

Such experiences do not necessarily undermine faith in traditional healers. The lesson drawn from this particular incident was that "there are two kinds of matan dook, one helpful, one deceitful."

Opinions towards biomedicine and traditional healers may be split within a household. For example, the father and maternal relatives of a boy who had broken his arm disagreed about whether he should be treated in the hospital or by a traditional bone setter. In the end, the father prevailed, and the boy was taken to the hospital. When the bone failed to heal, however, the boy's maternal relatives became angry with the father, arguing that the child should have been taken to a traditional practitioner.

Finally, it should be pointed out that some clients of traditional healers are hesitant to talk to researchers because some matan dook have bad reputations. Some East Timorese also believe there may be something "primitive" or shameful about traditional healers. For these reasons, the DHS and other surveys may underestimate community use of traditional healers and birth attendants.

In sum, perceptions of disease aetiology affect health care decisions. Attitudes towards "foreign medicine" are generally positive and even regular clients of traditional healers display a willingness to also seek out biomedicine. But there is a considerable range of attitudes towards traditional healers. Traditional healers and birth attendants continue to attract a fairly large clientele, although several research participants avoid their services altogether. Reliance on traditional healers or self-care may have a larger negative impact on reproductive health, which is often ranked low as a health risk.

\section{Staff attitudes to patients and community relations}

It was beyond the scope of this study to conduct a service quality assessment. Information is based primarily on clients' perceptions and a few comments from nursing staff, doctors, and managers. Since the objective of this report is to shed light on problems in health service delivery, we devote less space to describing the positive experiences of health care workers and patients.

There was a general consensus that "health workers are important members of the community." Many patients reported that nurses and midwives were "friendly," "trustworthy," and "skilled."

Personally I trust the health workers. If they are working in the hospital it means that they have the capacity to do their job as nurses, doctors and midwives. If they didn't know how to play their role as health workers then I don't think that they would be working in the clinics. (Rural client) 
However, staff rudeness and negligence was a theme that came up frequently in discussions with clients and to some extent with health workers themselves.

Their job is more important than the priest's or the nun's, because they are the people who can save your life. I always trust them because they have studied, taken an oath, and trained for the job. I think they have enough skills but the service they give to patients is very poor - that's where they need more training. (Urban client)

If we say we don't understand something the nurses scold us or tell us to go clean up our ears so that we can hear better. We are scared to ask questions. (Urban client)

Cavalier attitudes can make some clients reluctant to seek out health care.

I had a friend who an accident on her motorbike. She was almost dead but when we brought her into the emergency room the nurses scolded her. They said, 'We are not your slave to correct your mistakes. Before you were enjoying yourself and now you come to look for us.' This makes us scared to go to the hospital. (Urban client)

Some clients also reported that government nurses did not explain pharmaceutical regimens adequately.

They don't explain anymore how to take the medicine. If you don't understand and you ask them, they get angry and scold us. It is worse when they give instructions saying $3 \times 1$ or $2 \times 1$. If you ask they respond saying 'go check yourself.' (Urban client)

Several clients complained that those with connections at the clinic received preferential treatment...

If they know you they will attend you first even though you came late. If they don't know you you'll be the last person even if you came early. (Urban client)

... which can in some cases lead patients to seek out private providers (see below for more information on provider choice)

If there are still lots of patients waiting, they won't attend us, they'll go for lunch. They don't care whether you are sick or not, therefore we feel that we'll be better off at the Catholic Clinic. (Urban client)

Some health workers also discussed problems in service interactions, though they tended to relate them to overcrowding of clinics.

You can't be soft with them, or they won't delivery the baby properly. They won't push hard enough, and this might even kill the baby. We had training to understand better how to understand their pain. But some of us are still rude. 
In at least one of the coffee regions, resentment among coffee farmers about low prices paid for coffee beans is affecting community perception of the Café Timor clinics:

They say, "Those who are working in the CCT clinic are doing business," so they don't like us sometimes. This is a big problem for CCT ... recently in they stole the SSB radio from one of our clinics. The community thinks that the coffee price is too low and they think we rip them off. Some of them say, "They are selling our coffee and bringing medicines to us" [i.e. instead of paying a fair price?]. (CCT worker)

Another nurse though noted that hostility was reserved solely for the commercial, and not the health, division of the Cooperativo Café Timor.

We are in a different division from the one that buys coffee. Sometimes because they don't pay well the farmers for the coffee people come and threaten them with machetes. But the community tells us not to be afraid and just come to do our job. (CCT worker)

Overall, communities seem to have a generally favourable view of the CCT clinics, though it is worth noting that policies concerning commercial exchanges have the potential to affect client attitudes towards the clinics.

\section{Mistrust, fear}

Given the political circumstances in which many East Timorese first encountered biomedicine, it is not surprising that historically there has been some resistance to the use of government facilities. One "bad encounter" with biomedicine may be enough to discourage future visits.

Once when my kid got a fever I took him to the hospital and they gave him a needle (sona) and straight away he died from this. And now I'm afraid -- so I just use the traditional medicine I plant in my yard. (Urban client)

On the whole, a categorical refusal to seek health care, however, appears to be relatively rare (though various forms of "traditional medicine" are commonly used in conjunction with biomedicine - see above). There is fairly widespread confidence in the skills of health workers.

A USAID report on gender issues found that there was lingering mistrust of government health clinics in some areas due to abuses in provision of contraception during the Indonesian era (Diamond 2004). This complaint did not come up in our discussions. However, in one rural district, there was a report that community members who had supported integration with Indonesia were now afraid to visit the CHC.

\section{Fears about recovering the dead from hospitals}

There is a fear, especially in some rural areas, of hospitals as places "for dying." This perception may dissuade some from following up referrals from CHCs to the regional hospital. Some clients believed there was a shortage of mobil jenazah, vehicles 
used to return the bodies of the deceased, compared to the Indonesian era. Or in other cases, there was a fear that costs of transportation would prevent the family from performing proper funerary ritual (see also Mize 2004:14). Reluctance to seek hospital care is due not only to the fear of dying. It is also linked to a perception that families often encounter difficulties in recovering the bodies of the deceased from hospitals and to cultural funerary practices and beliefs.

Some people don't go to the hospital because they think if they die at the hospital there will be no transportation to bring them back to their homes. (Rural client)

That's why they don't go to the Dili hospital. They think the hospital is for dying, not for getting better. They believe it's not right to put the body on ice. They think, if we die our place will be that place, the "frozen place" (gelo fatin). The body has to be buried soon, at home, so the crying (halerik) can be done. If not, then any relative could get sick or have an accident [i.e. caused by spirit of the deceased]. (Urban worker)

A failure to perform funerary rituals such as burial, crying, and payments to affines can thus anger the spirit of the deceased, and endanger his family.

The cold place - that's not for human beings. The spirit will get angry and keep chasing us ... thinking why doesn't my family do the rituals? (Urban worker)

\section{Physical access to clinics: distance, transportation and costs}

Distance and transportation difficulties are major barriers to the utilization of health care facilities. According to the DHS, 25 percent of households have to travel two hours or more to reach their usual provider, a figure that rises to 35 percent for the poorest families. Furthermore, distance and difficult transportation were the dominant reasons cited by the 16 percent of respondents who never use the health care facility closest to their homes. While discussions with clients generally support these findings, two qualifications can be made.

First, clients made clear that distance is not the only significant barrier to health care utilization, as we discuss in other sections of the report. And second, willingness to make the journey to health facilities also depends on the perception of the health risk.

Given a long standing tradition of home birth and widespread views that pregnancy is not a health risk, distance and transportation problems are thus an especially significant barrier to hospital birth and ANC.

The first time I gave birth my neighbour helped me. My husband went to look for a taxi but by the time he got back the baby was out already. I wanted to give birth at the hospital but there was no transportation. (Rural client)

I have ten children -- one is passed away and now I have nine children. I had the first one at the hospital, the rest I gave birth at home since we live so far away form the hospital. (Urban client) 
Preventative health care may also be neglected more quickly due to access barriers.

Those people I know who live near by get a complete vaccination but those who live far away sometimes don't complete the vaccination for their kids. (Rural client)

Remote communities may also have inadequate access to emergency transportation.

Here we don't call ambulances because we are too far away and the road is very bad so the ambulance doesn't want to come when we call it. (Rural client)

Transportation costs can also be a significant barrier for rural communities. Since incomes for farming communities have substantial seasonal variations, there may be times of the year when there is simply no money available for transportation or health care costs. Some rural residents are also hesitant to go to the hospital in part due to fears of unknown costs.

Since villagers don't have money, they think twice about going to the hospital. They worry about having money for food, for transportation - or wonder what will happen if they have to stay overnight. (Rural client)

\section{Pharmaceutical availability}

Another major theme in group discussions was the availability of medicine at both government and private clinics. The problem has unequal distribution. In both urban and rural regions, some clinics seem to currently have an adequate supply, while others experience periodic shortages. (Private clinics in Dili that have had problems with pharmaceutical supplies have requested government assistance.) Note that since the research did not attempt to evaluate management and administrative procedures, it is difficult to identify factors contributing to the shortages. One rural worker though claimed that with the centralization of the pharmacy supply system in Dili there has not been adequate management of supply at the district level.

Drug stockouts have a number of implications for health service utilization and health outcomes. Household expenditures on pharmaceuticals may be significant for the poor, directing scarce resources away from other areas vital to health.

Sometimes we go to Dr. ___ [a private practitioner] to get cured. The problem is the medicine there is very expensive. During Indonesia times if you had $\$ 5$ you could buy good quality medicine. But now you'll have to spend \$50-60. (Urban client)

In rural areas, drug stockouts do not seem to have a large impact on provider choice. If a clinic runs out of a particular medication, patients will be referred, when possible, to another provider. In one rural area, however, a client requested that a mobile service formerly run by a Catholic organization resume service to his village because the CHC "never have enough medicine." He was told by the nuns that they no longer continue the mobile clinic "because a CHC clinic has opened in your area." 
But in Dili, clients can procure pharmaceuticals from a greater range of sources, including a number of private practitioners, private pharmacies, or informally, from health workers. A pattern of stockouts may undermine public confidence in government facilities, leading some clients to go to private providers operating out of pharmacies as a first resort.

Sometimes I spend up to $\$ 15$ to buy the medicine that is prescribed by a doctor. I think the government needs to increase the quantity of medicine because there are so many patients and not enough medicine in the hospitals and clinics. (Urban client)

The medicine in this clinic is stronger than the one at the main hospital. (Client at private practice attached to pharmacy).

At the hospital, the medicine given is not complete or they don't have enough medicine. Some people say that when they complain of illnesses such as fever, cough and cold to the doctor, at the end they only get cough medicine. (Private pharmacist)

Nurses also noted frequent delays in the delivery of pharmaceuticals

The lateness of the medicines really affects the services that we provide. Delays are some times up to a month or even more. In the pharmacy we have a formula to make the calculation but when we get the medicines they do not match our calculation. (Rural worker)

Self-medication and treatment by inadequately trained pharmacy staff can themselves create health problems and leave clients vulnerable to misinformation about pharmaceuticals - a serious problem found in many developing countries (see Nichter 1996).

Some patients go to buy medicines at the pharmacy without getting any prescription from the doctor. Some times they buy the medicine that is not right for complications that they have. The big question in my mind is sometimes the doctors give them the prescription but do they really have the money to buy the medicine? (Urban worker)

In some cases, shortages have led clinics to provide less than a full course of antibiotics.

If we don't have enough, we give them just three days worth and then tell them to come back to get the rest in two to three days. (Rural health worker)

Bottlenecks potentially contribute to drug stockouts. For example, there was a report of drug stockouts at one urban $\mathrm{CHC}$ due to overloading of the clinic with patients from other areas of Dili.

One thing that can make us frustrated is sometimes a lot of patients come to [our $\mathrm{CHC}$ ] and ... we give them prescriptions but when they go to the pharmacy the drug is not available. This is because there are patients coming from other 
areas in Dili [i.e. which are served by other CHCs]. I think all the clinics provide the same medicines but we don't know why they come to us while there are CHCs in those places. Anyway, when they come to us we can not refuse them. (Urban health worker)

Some health workers complained about increased bureaucratic obstacles to maintaining pharmaceutical supplies compared to the system during the Indonesian era.

In Indonesian times the bureaucracy was not that complicated because if you ran out of medicine you could just get a letter and show it to the person who is responsible for the medicine. But now you have to go through many processes to get the medicine. (Urban health worker)

Low salaries for health care workers as well as the large number of unemployed nurses may be creating financial pressures to augment income through informal selling of pharmaceuticals.

\section{Provider choice: public and private}

Provider decisions are affected by a number of factors, including: distance, cost of treatment and transportation, staff attitudes, availability of doctors, perceived quality of service and pharmaceuticals, waiting time, cleanliness, and the urgency of the patient's condition. The relative importance of each factor varies considerably. It should be pointed out that many clients do not perceive significant differences in service quality between NGO and CHC clinics but instead make their choices according to convenience of location. For some urban clients, the main distinction is not "government" and "private" but "hospital" and "clinic" - whether private or public (see below).

Cost is a significant factor for many. Even very modest registration fees charged by Catholic clinics, for example, discourage some patients from seeking care.

"The [Dili CCT] clinic is for middle class people and the hospital is for normal people." (Urban client)

"Only people with money can go to the clinics run privately." (Urban client)

However, many patients are willing to pay for a private health clinic, especially if it is located nearby, has shorter lines, allows for consultation with a doctor, or is perceived as having "better medicine." Fees range from a registration card (\$1 at many Catholic clinics) to a "full blood test" (around $\$ 10$ ) to a consultation plus pharmaceuticals ( $\$ 40$ or more).

Sometimes I go to the Catholic clinic because there are too many patients at the CHC and I don't have the patience to wait. I don't mind paying if it's quick. (Rural client)

For others, a belief that medicines available from private providers are more plentiful or "stronger" affects provider choice. 
The CHC only gives you medicine for two or three days. But Dr. __ [a private practitioner] gives us a prescription to buy medicine that cures us. (Urban client)

If they have money then they will go to the nuns' clinic because they will get an injection. But if they do not have money then they come to the other two clinics [i.e. $\mathrm{CHC}$ or $\mathrm{CCT}$ ]. (Rural worker)

I usually go to the hospital to get the treatment but if the medicine is not working I then take them to this clinic [run by private practitioner] because the medicine here is stronger than the one at the main hospital. Even though I have to pay in this clinic my kids get well quicker compared to the main hospital. (Urban client)

As we have seen, there was a willingness to combine traditional cures with biomedicine. Similarly, many clients do not hesitate to visit various providers sequentially if pharmaceuticals are not available or do not "work."

If the $\mathrm{CHC}$ runs out of medicine, they refer us to the Catholic clinic. Same thing if the Catholic clinic runs out of medicine, especially medicine for malaria. This happens often. (Rural client)

First we go to the CCT then if we don't get better we go to the CHC. If the medicine still doesn't work then we will go to the Catholic clinic, and then sometimes even back again to the $\mathrm{CHC}$ to get a referral letter for Dili. (Rural client)

\section{Provider choice (in Dili): hospital versus clinics}

Some urban clients expressed a preference for the hospital over clinics, whether government $(\mathrm{CHC})$ or NGO. This preference has a few implications. First, the policlinic at the Dili hospital may be overloaded with cases that would be more appropriately handled by CHCs or NGO clinics. Second, the preference for the Dili hospital policlinic may be related to the fact that patients are attended by a doctor not a nurse. One nurse reported a decline in client confidence in nurses since the Indonesian occupation due to a growing belief that they are an inferior or "lower class" version of a doctor.

I think that in the Indonesian era people were more enthusiastic about coming to the CHC compared to now. I think they probably think that the $\mathrm{CHC}$ is lower class or whatever compared to some others - the main hospital, or [private] doctors, professors, specialists. They think that the doctors and the nurses who work in the $\mathrm{CHC}$ have a lower education and are not really trusting trust us. (Urban health worker)

It may thus be appropriate to set up a triage system at the policlinic to make more efficient use of the doctors' time (e.g. spending more time with patients who need a physician's diagnostic expertise). And third, preferences for the policlinic may also indicate quality problems at $\mathrm{CHCs}$. 
When I got sick I went to the CHC and they gave me medicine but didn't do a blood test. I didn't get better so I went to the hospital where they cured me after they did a test that said I had malaria. (Urban client)

(It should be pointed out though that staff rudeness was encountered both at the hospital and at CHCs.)

\section{Maternal and child health and family planning}

The DHS reports that 90 percent of live births in the five years preceding the survey occurred in the mother's home and that only 19 percent of mothers were assisted by medical staff. Pregnancy is generally not perceived to be a serious health risk. This is perhaps related to a generally low interest in preventative health or to a view that child birth, unlike serious illness, is just a part of everyday life. Nevertheless, it was not uncommon to hear parents express strong preferences for medically-assisted birth. Awareness of the health benefits that midwives and hospitals provide, however, often paradoxically coexisted with the continued practice of giving birth without a professional birth attendant.

I think the hospital is the best place to give birth because there are doctors and midwives always standing by ... I think giving birth at home is also good because there are traditional attendants or our grandmas who have the skill to deliver the baby. But this does not guarantee that the mum and the baby will survive during the delivery. (Rural client)

Sometimes I give birth at home and sometimes I give birth at the hospital. If I think I can handle it at home then I will giver birth at home, if I think I can not handle it better when giving birth at home then I will go to the hospital. (Urban client)

High rates of home births without medical assistance and under-utilization of ANC, even among couples with higher levels of education, is due partly to a preference for following tradition or family precedents.

Sometimes those who are quite well educated don't want to come for antenatal care - maybe they think they know everything. Some come after 7 months and they discover their baby is abnormal. We ask them why didn't they come earlier and they reply, "We got used to it, because we did the same thing with our first and second child." (Rural health worker)

A long tradition of procuring the services of traditional birth attendants persists in some regions ...

In every village there are a few dukun (TBAs) that help with deliveries. In the Indonesian era they were trained by the health department and used to work with the local clinic. Some women go to the dukun first ... as long as the dukun can still help them they will not come to a midwife, even one who is 
nearby. Now the government has forbidden this but in the rural areas people still trust them (TBAS). (Rural worker)

... Even though some TBAs expect a valuable gift in exchange for their services.

If they go to a dukun (TBA) they have to give a pig or tais (woven cloth) after the child is born. I think they probably don't understand if they come to the hospital they will pay nothing. (Rural worker)

In-laws may have considerable influence over their daughters-in-law in making decisions about ANC and where to give birth.

Sometimes their mother-in-law assists them at home in giving birth, that's why they don't come to see a midwife. Because their mother-in-law told the mother that she has assisted many childbirths in the family. (Rural worker)

In sum, knowledge is not enough. Even when respondents believe that medicallyassisted deliveries are safer many still choose to give birth alone or with the help of a relative or TBA. (There has been a considerable rise in deliveries at the Dili hospital in the past two years, however, according to an expatriate $\mathrm{Ob} / \mathrm{Gyn}$.)

\section{$\underline{\text { Part 2: Problems in service delivery and human resource issues }}$}

\section{Training}

Demand for more training was high among health workers in both the private and public sectors and in urban and rural areas. Some workers stressed the need for all nurses to be included in trainings

If there is a training from the government they will include only one or two people from our district to attend. There are quite a lot of our friends here haven't attended a training ... The rest of us can only rely on the knowledge that we got at school but there has been so much change in the medical domain. So if it is possible we are asking the government to involve all of us in the future trainings. (Rural worker)

Private sector workers repeatedly requested inclusion in government training programs.

If possible trainings should also involve those of us from NGOs because the services we provide are not only for one or two patients but for the community in general. (CCT worker)

If it is possible, we are asking the government to involve private health workers in the future trainings. So far, CCT has not been involved in any trainings. (CCT worker)

I am from a Catholic clinic, and some of my midwife friends from the $\mathrm{CHC}$ have attended some trainings such as "safe motherhood" but we as private 
sector workers have not attended any such trainings. So I suggest that the private sector needs to be included in the coming trainings. (CC worker)

Some nurses requested additional training in prescribing pharmaceuticals.

Now we have a national drug protocol so if it is possible we are asking the government to hold a training on drug use for all of us. I think we have a problem with prescription, which is very inefficient. (Rural worker)

Another theme that came up in group discussions was the need for follow-up assessments of the effectiveness of training programs.

I don't think it is enough for us to only attend a training once only in a while. I think they need to have a program to review the previous training in order to assess whether it was enough for us to do our job. If it is not enough the same training needs to be hold next time. (Rural worker)

\section{Compensation and pension}

There was a general feeling among workers at different types of providers and in different regions that compensation was inadequate. Note there are significant differences in NGO, Catholic and government health worker salaries: Government workers earn US\$123 at level 3 and US\$155 at level 4. Salaries in Catholic organizations tend to be somewhat less, while CCT nurses earn around US\$220 at a comparable skill level.

Some people say, "Don't play with fire or you will get burnt." Similarly, if we play with disease we will get sick. Because if you are level 3 with a salary of $\$ 120$ it is not enough to buy food even. We can talk a lot about health but what can we do if we are not healthy? (CHC rural worker)

Some workers complained about pension policy for family members of health workers who die or become disabled. (A major draw for public sector employment was the hope of a retirement pension -- see below).

My friend was doing his job and got in an accident and died. His family got compensation only for two months plus the coffin. And the government gave the compensation too late. This makes people frustrated. To my mind the government should acknowledge his work. Sometimes when we go do our job in the rural areas we might not go if we think the government will not support our family if we get in an accident. (CHC urban worker)

Other workers felt that their work load was higher than it is for civil servants in other sectors even though compensation is the same.

We work more hours than other sectors, for example, the education sector. Some teachers they start to work at $8 \mathrm{am}$ and they finish at 10am but their salary 
is the same as ours. For them the school holidays last for three months long.

But we are working all the time. (Rural worker)

Rural workers who live far from the clinic report that salaries do not cover transportation costs or accommodation. One worker suggested that the costs of transportation to work may contribute to absenteeism.

Sometimes I need to borrow money from my neighbours in order to pay for my transportation. Or sometimes I decide not to go to work because I don't have enough money for transportation. We are happy to do our job but we don't feel happy about our economical situation. (Rural worker)

And finally, low salaries may contribute to brain drain - either overseas or to the private sector - or induce some workers to augment their income in the nascent informal health care market.

Now the salary of the government workers is not enough [compared to the Indonesian era]. If people don't earn enough they will have to do some other business. After they finish work they might sell drugs. We can not stop people from doing this because they don't have money for living. Now there are also a lot of people who have left East Timor to work, for example, in Ireland, Japan, and Malaysia. (Urban worker)

\section{Management, supervision, accountability}

This study is based primarily on group discussions with health care workers, not managers, and there has been no systematic evaluation of accountability and performance problems in the different providers. Based on worker perceptions, however, we can indicate a few differences between in supervision and accountability practices in the public and private sector.

There seems to be more supervision and accountability in the private sector overall. CCT reviews staff performance before renewing a contract and conducts regular quality assessments (however, it is not clear how effective these are).

Since we are private the rules are very strict. If you come 10 minutes late, tomorrow you will get called to the office to talk about it. If you continue three times then you'll be out. The discipline in working is also controlled tightly. Once again since we are working with private NGO we have to follow what the NGO ask us to do. If not, even though you have a one year contract it can be decreased into 6 months contract. (CCT worker)

An important aspect of working in the private sector is servicing the patient with good manners. If I instruct them (the other staff) and they do not listen because I am too young for them, I'll have to go to talk to the head of the clinic. If it doesn't change unfortunately they'll have be to fired. (CC worker) 
CCT also provides a job description to its workers that they must sign when they are recruited, while some government workers complained that their responsibilities were only vaguely defined.

In the public sector, there are some accountability mechanisms in principle. Staff are given a verbal warning (lisan) for a first offence, a letter (tulisan) for a second. A third offence requires a meeting with the district office. In practice, however, many health workers seem to be unaware of these measures. And some participants from rural $\mathrm{CHCs}$ in fact complained about the absence of supervision and monitoring mechanism of any kind.

In the CHC, those who come to supervise us are from the WHO ... they do not directly reprimand us, but just observe what work we do. Then they will just put a check or cross on their supervision sheet. They do not tell us whether or not we do things properly ... We do not know where are the weaknesses because they do not tell us. (Rural worker)

There is little use of incentives aimed at improving performance, except apparently at a few Catholic clinics. Several participants were enthusiastic about the idea of incentives when it was raised in group discussions and specifically requested training as a reward for good performance.

I think in Indonesian time those who did well in their job got a special reward. This is good because it motivates others to do well in their job. I suggest that those who do well receive extra training overseas. I think this will create a working environment that will improve the quality of our service. (Rural CHC worker)

\section{KKN (Indonesian term for “corruption, collusion, and nepotism”)}

Informal payments -- direct payments to health workers for ostensibly free public health services -- do not appear to be a problem in Timor-Leste. While it is fortunate that the health system has avoided a problem that plagues many developing countries, there are other kinds of financial transactions (from corruption to payments that are not technically illegal ) that may undermine efforts to improve access to health care.

Several workers complained about nepotism in government hiring and transfers. Apparently there is no formal mechanism for applying for a transfer within the public sector.

New job positions - they just pretend they are open. Sometimes 1,000 people come to the test to apply but actually people inside have already chosen a boot sira nian oan ("big person's son"). It's just so people won't see the nepotism. (Urban worker)

There is no official way to transfer for the time being. But some people do this through "KKN." If you know someone who has a high position in the Ministry they can transfer you to a place of your choice. One of my friends did it, she moved from (Urban worker) [rural subdistrict] to Dili because she knows someone. 
Those who have relatives that have been working in parliament can get transferred from a rural area. So my suggestion to the government is to give special compensation (tunjangan khusus) to those who are working in the rural areas just like in Indonesian times so they will be induced to stay in their community. (Urban worker)

One rural nurse was also concerned about unexplained deductions from her salary.

I think there might be a corruption in the health sector but we are not in the position to investigate who is doing it. Sometimes we hear there are some funds for certain things, but the money has not been used entirely . . And the other thing is sometimes our salary is cut and we don't know why and where the money goes. So this is not clear to us and we are very concerned about this. (Rural CHC worker)

Reports and speculation concerning theft of medicine from clinics and resale to pharmacies came up a few times during group discussions, though workers seemed unsure about the extent of the problem.

We suggest, if it is possible, that the government or WHO form a body to investigate and control the activity of all the chemists and clinics. So that they know how the medicines are used in the clinics. Sometimes in Dili there are a lot of hospitalisations and there are no medicines in the hospitals for the patients. This is a big problem. (Rural worker)

But some workers also argued that there was a perception of drug theft among clients simply because the same brands of pharmaceuticals available at the CHCs were also sold by private pharmacies (which had been opened by nursing staff to supplement their income). They argued that the community should be informed that these pharmacies were legitimate businesses that were importing drugs from Indonesia.

VIP wards in the government hospital may also fuel perceptions of KKN and frustration with quality of service and staff attitudes among non-VIP users. The direct payment of $\$ 10$ to $\$ 15$ to nurses for use of these rooms may also set up a dangerous precedent of using cash transfers to health workers in order to gain access to higher quality service.

\section{Rural urban differences}

As mentioned above, some workers argue that rural postings should receive extra compensation (tunjangan khusus) - a practice that existed during the Indonesian occupation. Others argue that rural positions should be filled with staff who come from the district where they are posted.

The government needs to place in the rural areas people that come from that particular area and then provide them some transportation or bonuses to motivate these people to work in their community. (Urban $\mathrm{CHC}$ worker) 
But others disagreed:

I think it really depends ... if I come from the rural area and I have my house there, and my family are in the village, it is not necessary for me to stay in Dili. It's better to work in the village and look after my farm. (Urban private worker)

It should be noted that CCT has a policy of not posting nurses and midwives near their families, apparently so that family obligations will not contribute to absenteeism. In any event, many rural workers report feeling isolated. They request that they be notified of training opportunities and kept informed of new treatment protocols.

But here we don't get any information. We haven't been told at all about this [an upcoming test to participate in a training session]. I am asking the Ministry of Health to announce any information like this nationally so that every one can get the same chance to sit for the test to study (Rural CHC worker).

Those who are working in the city know about current diseases. For example now people don't use aspirin anymore, but in the rural areas we are still using it. If I were working in the city I would be happy because I would know about training, meetings and new medical technology. (Rural CHC worker)

Rural workers also complain of a lack of opportunities to transfer to other districts and gain new experience.

\section{Labour market choices}

Many developing countries with a large private sector have encountered a growing problem of "internal brain drain" - migration of health workers out of the public sector (Chen et al 2004). So it should first be pointed out that retaining public sector workers does not appear to be a problem in Timor-Leste, at least for the moment. In part this is likely due to a surplus in the labour supply (many nurses formerly employed in the Indonesian administration were not re-hired after Independence). Group discussions, however, also revealed that many workers have a strong preference for working in the public sector. The major attraction of a government post for many is that it offers - or is perceived to offer -- greater security and a retirement pension.

I think I prefer to work in the government sector than the private sector because in the private sector your contract can be terminated any time. But in the government sector you will work until you reach 50 or 60 years old then you will retire. (Rural worker)

This was true notably for some private sector workers as well, even for those who receive a substantially larger salary than government workers.

Personally, I would choose the government sector. Because if you work in for the government you will get a retirement benefit. In the private sector, as long as you are healthy you can work but if you are sick you will have to stop. (Rural private worker) 
This preference was surprising in light of complaints about working hours and inadequate compensation in the public sector. The preference for public sector work may be related to the long period of instability in Timor-Leste and especially the uncertainty surrounding health sector employment in the post-referendum period. Several private sector workers reported that they had first sought government employment but did not pass the exam.

But some workers also expressed pride in being a civil servant in the newly independent government. Thus some form of "intrinsic motivation" - which is often attributed to NGO and faith-based services - also exists in the public sector ...

I was working in the private sector then there was a recruitment from the government sector and I started to apply because I felt that I was called to do something for this nation. In the end I was selected so I moved to the government sector. (Urban $\mathrm{CHC}$ worker)

... Or can motivate an NGO worker with a higher salary to try to obtain a CHC post.

I would prefer to work in the government sector because this is for the nation and we have a great contribution to our country even though we don't get that much paid. But for the time being there is no recruited by the government and we can not keep waiting while there is an opportunity to work in the private sector. (Urban private worker)

Some Catholic workers said they would prefer to work in the public sector because they would then receive extra training.

Nevertheless, some health workers were aware of higher NGO salaries and better benefits (such as transportation) and viewed them as a potential lure to the private sector.

If the private sector paid more than the government sector then personally I would choose the private sector . . . to support my family economically. So I suggest the government should create balance in the salaries so that neither the private nor government sector attract more people to work there. (Rural CHC worker)

Personally, as a health worker I have the responsibility to do what I can do for the nation. But if the government can not look after us I think people might abandon their job to work in the private sector. (Rural CHC worker)

So, sometimes we think that to work in the government sector is to become a slave. That's the reason why some nurses want to work in NGOs - or why some want to do their own business. There are a lot of NGOs around, and those who are working there have a smaller working load and a higher salary. (Rural CHC worker)

There appear to be very few instances of public sector nurses or midwives seeking to supplement income through private sector work or by requesting informal payments at 
government clinics. A number of doctors in Dili have opened private practices in evening hours.

\section{Discussion and policy implications}

To conclude we relate findings of this study to international evidence and discuss some of their policy implications.

\section{Barriers to utilization}

- Sociocultural knowledge and practices, service quality issues, and geographical remoteness all act as barriers to health service utilization. Expanding coverage frontiers would likely increase utilization of services. However, local systems of ethnomedicine - including understandings of health and disease, and reliance on herbal medicine and traditional healers and birth attendants - play a significant role in health seeking behaviour.

- Information on client attitudes towards "Timorese" and "foreign" medicine might usefully be integrated into health promotion and education programs. For example, health or community workers might address community perceptions of health care facilities as places for "dying, not curing." The model of "positive deviance" - building on community knowledge and practices by encouraging existing health-promoting practices - may also have some application. Such engagement may provide greater opportunities to discourage un-healthful practices. For example, "sitting fire" (tuur ahi) after birth has the benefit of protecting infants from the cold in mountainous areas while smoke may contribute to respiratory tract infections.

- There are also opportunities to increase the efficacy of herbal remedies currently used by integrating them with clinical services (e.g. AFMET in Los Palos and Clinic Paz in Dili.)

- Many clients seem to be partially aware of the benefits of ANC and medically-assisted birth, and yet still not make use of these services. Given the long established traditions of home birth without professionally trained birth attendants, increasing the number of midwives with community ties may be able to significantly boost demand for maternal health services.

\section{Human Resource Issues}

Unlike many developing countries, Timor-Leste does not seem to be experiencing a crisis in its health worker labour markets, probably due the high number of unemployed nurses, a legacy of the Indonesian civil service system. However, emigration of qualified nurses from developing to developed countries is occurring in a number of countries. And studies have found that where nurses feel "overworked and underappreciated" there are higher rates of absenteeism (World Bank 2004). Among health workers in both sectors, there appears to be a high degree of intrinsic motivation - "I have the 
responsibility to do what I can do for the nation" (as well as anxiety about job security). This can be seen as a form of social capital that can be cultivated by making human resource policy more responsive to staff concerns.

\section{Training, transfer, and compensation policies}

- A common theme in discussions was a desire for more training. Rural health workers in particular felt that there were not enough opportunities for training and that existing ones were not adequately publicized. There was some evidence that training programs could be used as an incentive to work in rural areas or as a reward for performance. Expatriate doctors reported that a competition for overseas scholarships significantly improved morale among doctors.

- Given a perception of KKN in hiring and transfer among health workers, greater transparency may help improve motivation and morale.

- Group discussions revealed a widespread dissatisfaction with compensation and pensions. At the same time, many nurses and midwives expressed a preference for work in the public sector, apparently due to a form of intrinsic motivation as well as concerns about retirement pensions. This information may thus be of use to policy makers when they formulate a pension policy. It should also be noted that many workers were unsure about retirement and workplace injury benefits currently offered.

- Some workers felt that is was unfair that they were hired at a level below their skills and experience, especially given the lack of opportunities for promotion.

- Opinion was divided on the issue of extra compensation for rural workers (a policy followed by the Indonesia administration). Some believed extra compensation would help offset the hardship of a rural post. Others argued that if workers were posted to rural areas near their families they would benefit from support networks and be able to supplement their income through agricultural work.

- A lack of transportation for some staff posted to remote areas creates hardship and perhaps contributes to absenteeism.

\section{Transportation and mobile clinic policies}

- Mobile clinics: There are significant transportation problems in reaching remote communities. Interruptions in mobile clinic services lower community confidence in health care. Converting some mobile clinics to fixed clinics may thus improve utilization rates in remote areas.

- There may also be opportunities to expand coverage through coordination between public and private mobile clinics.

- There were reports that district health managers and their deputies are driving vehicles that were donated explicitly for operational use. 
Supervision and accountability

- Workers request that new training programs are accompanied by follow-up assessments.

- Training might usefully cover professionalism and community relationships.

- There is some evidence that CCT's supervisory practices have a positive impact on health worker motivation and morale.

\section{Staffing levels and workloads}

If the $\mathrm{MoH}$ decides to review staffing levels, this study suggests a few points to consider.

- It was beyond the scope of this study to measure actual working hours at various clinics. Many, but not all, nurses felt that they were overworked and were consequently not always able to provide adequate service.

- Group discussions suggested that there was considerable variation in case loads among the different clinics. There may be opportunities to reassign some public sector health workers to even out waiting times for patients and create fairer workloads for staff. There may also be opportunities to redistribute case loads among public and private sector clinics. (See below)

- There were widespread community confusion about pharmaceutical regimens, maternal health, and communicable diseases, and complaints of staff rudeness and waiting times. In these circumstances, improvements in the quality and length of patient staff interactions may increase utilization of health services.

\section{$\underline{\text { 3. Public and private sector coordination and partnerships }}$}

One of the principal aims of this study was to provide information on differences among public and private providers from both client and health worker perspectives. In this concluding section we discuss how research findings bear on opportunities for -- and constraints on - coordination between the private and public sectors.

Since the 1990s, the "public-private partnership" has become fashionable and controversial in the domain of international public health. The director-general of WHO, for example, announced a new policy of exploring "open and constructive relations with the private sector and industry" in her first speech after her 1998 election. Private foundations and government agencies, particularly in the United States, have taken an active role in creating and funding such partnerships in the developing world (Reich 2002, Widdus 2001).

For supporters, partnerships combine and capitalize on the complementary strengths and capabilities of different organizations, thus "minimizing market and government failures in providing services" (World Bank 2004). Partnerships can also address health equity issues, for example, access to pharmaceuticals. For detractors, however, partnerships are the first step down a slippery slope leading to "institutional 
capture" of public institutions and government agencies by corporations. ${ }^{3}$ Partnerships may jeopardize social safety nets, leading to "islands of excellence in seas of underprovision" (Buse and Waxman 2001). ${ }^{4}$

A larger private sector in developing countries can pose particular threats to the poor. Ensuring the quality of private practitioners may require regulatory powers that fall outside of the capacities of health ministries. In India, for example, the rapid growth of the private sector has been accompanied by a widespread problem of under- or unqualified private providers serving the poor (Kumar 2000). ${ }^{5}$ A larger private sector can also be associated with informal marketization of public services. ${ }^{6}$ Some of the problems with for-profit providers are avoided by NGOs, which often benefit from strong intrinsic motivation and a professional ethos. However, a larger NGO role in the health sector of poor countries is not without risks as well. Evidence from Mozambique, another poor, post-conflict country, suggests that an influx of NGO aid into the health sector can fragment primary health care, undermine self-determination in health policy and public confidence in government services, and augment regional and class inequities in coverage (Pfeiffer 2003, Cliff 1993).

A health system divided into public and private sectors of different quality can also hinder efforts to encourage participation and ownership of health care (Faveret and Oliveira 1990). In Timor-Leste, the influx of foreign aid and expertise in the postreferendum period expedited the reconstruction of the health sector under difficult conditions. However, NGO involvement in the health sector also brought problems -- for example, large, expensive projects that the government cannot afford to fund or maintain after NGO withdrawal (Tulloch et al 2003, Morris 2001). Some current NGO projects may create expectations for services the government cannot at present provide. The presence of international NGOs can create an "unusual social interface" between highly educated expatriate workers and extremely poor communities. Such working relationships can have a beneficial effect on capacity-building, but they can also contribute to local processes of "exclusion and humiliation that undermine equityoriented efforts in development" (Uvin 1998). ${ }^{7}$

\footnotetext{
${ }^{3}$ Thus reshifting health priorities, for example, away from the more difficult task of capacity development to programs such as drug donation with a higher chance of success (Buse and Waxman 2001)

${ }^{4} \mathrm{~A}$ few caveats should be kept in mind in assessing the merits of public-private partnerships -- and the relevance of the debate surrounding them - for Timor-Leste. In much of the discussion of public private partnerships, they are defined as a working relationship between at least one not-for-profit organization and one private for-profit organization. NGOS are thus sometimes placed in the "public" side of the equation public-private partnerships (Reich 2002: 4). Though NGOs are independent of the state, according to this line of reasoning, they act in the pursuit of public rather than private interests. By this definition at least, most partnerships in East Timor - both those existing and those being considered -- are really "publicpublic." In any event, partnerships in the health sector will involve different kinds of opportunities and concerns if commercial organizations are excluded.

${ }^{5}$ For example, practitioners with a poor clientele frequently treated febrile patients with a one day treatment, arguing they were simply responding to the needs of patients who could not afford a peripheral blood-smear test (Kamat 2001).

${ }^{6}$ That is, the rise of informal payments to public providers, which has been documented in Africa, East Asia, and Eastern Europe (Belli and Shahriari 2002, Lindelow et al 2004).

${ }^{7}$ Another potential drawback to a larger NGO presence is the effect it can have on government health worker morale and performance. Higher private sector salaries can add to public sector workers' dissatisfaction, encourage informal payments, or contribute to absenteeism as workers take private sector employment to supplement their income. Salary differentials can lead to "internal brain drain" from public
} 
In sum, there is "no technical" answer to finding the right mix of public and private. Decisions have to be made according to political and social values, institutional cultures, and health challenges. It is also difficult to evaluate a priori efficiency and performance in public or private organizations. For example, in Tajikistan and Tunisia government providers have delivered high immunization rates, but in Cambodia and Haiti, NGOs have done so as well (World Bank 2004).

Some of the problems we have indicated here will be of less relevance as the presence of international foreign agencies in the health sector declines, though perhaps they are worth considering as potential risks in the future. We turn now to consider benefits that partnerships and improved coordination between with private providers may yield:

- First, it should be noted that public-private partnerships already exist in embryonic form in Timor-Leste, for example, the management of the TB program by a Catholic clinic, and coordination of malaria diagnostic and treatment services between CHCs and Catholic clinics. Workers in both sectors also called for expanded coordination and division of services among the different providers.

- Given the fact that access to primary health care continues to be a problem, there are opportunities to reduce bottlenecks and expand coverage by coordinating with private providers. For example, patients at overloaded CHCs in Dili could be redirected to under-utilized Catholic clinics.

- Coordination with private providers also presents opportunities to ensure that government treatment protocols are implemented - and duplication of services avoided. In cases where private providers lack essential diagnostic services or drugs, the $\mathrm{MoH}$ may consider supplying these, especially if some $\mathrm{CHC}$ patients are redistributed to private providers. Such strategies though may require monitoring. ${ }^{8}$ A justification for this policy might in part depend in part on the capacity of the central pharmacy to keep public clinics adequately supplied. A second option would to provide the MoH's defined basic package of services through a mix of public and private clinics, though this will probably require enhanced communication. Research suggests that a more comprehensive approach to partnerships that aims to improve private providers' knowledge and skills, externally monitor and evaluate implementation, and encourage users to demand good care has best results (World Bank 2004).

- Another issue to consider is whether fees charged by some private providers will undermine health equity or efforts at strengthening public understanding of health care as a right.

to private clinics (Pfeiffer 2003). This last possibility seems fairly unlikely in the immediate future given the fairly large supply of health workers seeking employment. Nevertheless, during the period of reconstruction, higher salaries paid to local staff of international agencies contributed to discontent with government compensation (Tulloch et al 2003).

${ }^{8}$ A study found that antimalarials supplied to pharmacists had been sold to street vendors who resold individual tablets at a higher unit cost (Foster 1991). 
- Increasing coordination with private providers may also help channel donor funding to the most urgent health priorities. In some regions, staff complained of power and water shortages at $\mathrm{CHCs}$, for example, while NGOs funded projects that do not fall within the government's district health goals and can not be duplicated on a national level.

- Enhanced coordination among clinics can improve MoH's ability to monitor public health.

- Drug stockouts are a problem in both public and private providers. There were reports of health workers informally selling pharmaceuticals, though the extent of the problem is unknown. One option would be to subsidize pharmaceuticals to private clinics in order to reduce client out-of-pocket health care expenditures that weaken equity and potentially adversely affect health, especially among the poor.

- Given the growing presence of pharmacies in the health care market, at least in urban areas, and the lack of familiarity with "foreign medicine" among the general public, tighter regulation of private pharmacies may be appropriate.

- Partnerships with civil society organizations and community cooperatives may be particularly effective in the areas of self-care and health promotion. Functioning as intermediaries between clients and providers, these types of organizations have in many parts of the world effectively reduced malnutrition, spread the practice of exclusive breastfeeding, and educated parents about the use of oral rehydration solutions. Grassroots and small community based groups often out perform larger public organizations in providing community-level information and support (World Bank 2004). 


\section{References}

Asowa-Omorodion, F. I. 1997. Women's perceptions of the complications of pregnancy and childbirth in two Esan communities, Edo State, Nigeria. Social Science \& Medicine, 44(12), 1817-1824.

Atkinson, S., \& Farias, M. 1994. Perceptions of risk during pregnancy amongst urban women in northeast Brazil. Social Science \& Medicine, 41(11), 1577-1586.

Buse, Kent and Waxman, Amalia. "Public-Private health partnerships: a strategy for WHO." Bulletin of the World Health Organization, 2001, 79: 748-754

Chapman, R. 2003. Endangering safe motherhood in Mozambique: prenatal care as pregnancy risk. Social Science \& Medicine 57, 355-374.

Diamond, Nancy. 2004. USAID Timor-Leste Gender Assessment. DevTech Systems, Inc.

East Timor National Mental Health Project. 2003. Ministry of Health, Democratic Republic of East Timor.

Foster SD. 1991. Pricing, distribution, and use of antimalarial drugs. Bulletin of the World Health Organization 1991;69:349-63

Jefferds, M. D. 2002. "Concepts of iron deficiency anemia and public health measures in rural Costa Rica, Social Science \& Medicine, 55(7):1143-1156.

Jirojwong, S. 1996. Health beliefs and the use of antenatal care among pregnant women in Southern Thailand. In P. Rice \& L. Manderson (eds.), Maternity and reproductive health in Asian societies (pp. 61-82). Amsterdam: Harwood Academic Press.

Kamat, V.R. 2001. "Private practitioners and their role in the resurgence of malaria in Mubai and Navi Mumbai, India: serving the affected or aiding an epidemic?" Social Science \& Medicine. V52i6:885(25)

Kleinman A., Eisenberg L., and Good B. 1978. Clinical lessons from anthropological and cross-cultural research. Annls Intern. Med. 88, 251-258.

Krueger, R. A. 1994. Focus groups: a practical guide for applied research $\left(2^{\text {nd }}\right.$ ed.). Thousand Oaks: Sage.

Kumar, S. 2000. "Indian health organizations call for control of private sector health care.” The Lancet. V356i9247:2077

Lindelow, M., Serneels, P. and Lemma, T. 2004. The Performance of Health Workers in Ethopia: Results from Qualitative Research. (Draft paper.) World Bank. 
Livermore, C. 2002. Tuur Ahi: Childbirth and child death in Aileu, East Timor.

Mills, A, Brugha, R, Hanson, K, McPake, B. 2002. What can be done about the private health sector in low-income countries? Bulletin of the World Health Organization, April 2002 v80i4:325

Ministry of Health and National Statistics Office, Timor-Leste, and ACIL Australia Pty Ltd, University of Newcastle and the Australian National University. 2004. Timor-Leste 2003 Demographic and Health Survey. Dili, Timor-Leste: Ministry of Health.

Mize, L. 2004. Maternal and neonatal health in East Timor: Findings from the USAID situational analysis January 11-30, 2004 and recommendations for possible program interventions.

Morgan, D. 1998. The Focus Group Guidebook. Thousand Oaks: Sage.

Muela, S.H., Ribera, J.M., Mushi, A.K. \& Tanner, M. 2002. "Medical syncretism with reference to malaria in a Tanzanian community. Social Science \& Medicine, 55(3): 403413.

Nichter, M. 1996. Pharmaceuticals, the commodification of health, and the health caremedicine use transition. In M \& M Nichter (eds), Anthropology and International Health. Australia: Gordon \& Breach.

Pfeiffer, J. 2003. "International NGOs and primary health care in Mozambique: the need for a new model of collaboration." Social Science \& Medicine 56 725-738.

Reich, M. 2002. Public-Private Partnerships for Public Health. Cambridge: Harvard Univ. Press.

Sesia, P. M. 1997. Women come here on their own when they need to: Prenatal care, authoritative knowledge and maternal health in Oaxaca. In R.E. Davis \& C.F. Sargent (eds.), Childbirth and authoritative knowledge: Cross cultural perspectives (pp. 397-420). Berkeley, CA: University of California Press.

Soares, A., Martins, J., et al. 2004. Knowledge, attitude and practice on malaria in TimorLeste. University da Paz, Dili \& Menzies School of Health Research, Darwin. UNICEF, Dili and Insan Hitawasana Sejahtera, Jakarta, Indonesia.

Tulloch, J. et al. 2003. Initial steps in rebuilding the health sector in East Timor. Washington: National Academies Press.

UNICEF. 2003. Multiple Indicator Cluster Survey -2002, Republic of Timor-Leste. 
Van Schoor, V. 2003. Sitting Fire: a community-based study of home births and postpartum care in East Timor. University of Amsterdam Faculty of Social and Behavioral Sciences, Medical Anthropology Unit, August.

Widdus, Roy. "Public-private partnerships for health: their main targets, their diversity, and their future directions. Bulletin of the World Health Organization, 2001, 79: 713-720

World Bank. 2004. World Development Report: Health and Nutrition Services.

World Health Organization. 2004. WHO country cooperation strategy 2004-2008, Democratic Republic of Timor-Leste. WHO regional office for South-East Asia: New Delhi.

Yach, D. 1992. The use and value of qualitative methods in health research in developing countries. Social Science \& Medicine, 35(4), 603-612. 


\section{Appendix I: Methodology}

There has been a growing recognition of the value of health research that integrates quantitative and qualitative methods, especially in developing countries where there may be significant differences between biomedical and traditional concepts of illness, healing, and health promotion (Yach 1992). Focus groups were selected as a methodology for this study because they are particularly suited to understanding complex behaviour and motivations, and can provide contextual information missing from quantitative data (Morgan 1998). They also provide a forum for participants to understand each other's views and experiences. A group discussion thus provides participants with a context for exploring motivations that may not have been apparent to themselves before beginning the discussion (Krueger 1994).

The study combined focus group discussions with clients and health service workers with in-depth individual interviews. Focus group protocols were designed to promote open, honest, and nuanced discussion of potentially sensitive and complex topics. These discussions were held in local languages and led by researchers who received basic training in focus group facilitation. Due to the potential effect that status differences can have on the willingness of participants to speak openly, participants of similar socioeconomic and educational background were selected wherever possible. Recognizing the importance of maternal health and gender-based status differences, some focus groups of community members were composed of women only. Health workers consisted of midwives and nurses. Doctors, community leaders, traditional healers, and upper level management were not included in group discussions, but some were interviewed separately.

Group discussions and individual interviews were transcribed and translated by the research team while in the field. Key discussion themes were then identified and analyzed in relation to existing quantitative data.

Research was conducted in communities with access to different types of health care facility: government clinics, community health care centres, health posts, mobile clinics, and various types of NGO clinics. The following mix of five subdistricts was selected:

- Subdistrict I (Dili) was urban and had a mix of all three types of providers.

- Subdistrict II was rural and had a mix of CCT and government clinics.

- Subdistrict III was rural and had three types of providers, CCT, Catholic, and government clinics.

- Subdistrict IV was rural and had only a CCT clinic.

- Subdistrict V was rural and had only Catholic and government clinics.

Four focus groups with health care workers and five focus groups with health care users were conducted. Each group consisted of six to twelve participants. 
Breakdown of focus groups, by region (urban and rural)

\begin{tabular}{|l|l|l|}
\hline Region & Health Care Workers & Health Care Users \\
\hline Urban & 1 & 1 \\
\hline Rural & 3 & 4 \\
\hline Totals & 4 & 5 \\
\hline
\end{tabular}

Breakdown of focus groups, by sector (public and private)

\begin{tabular}{|l|l|l|}
\hline Sector* & Workers & Users \\
\hline CCT/Gov/Catholic (1 urban, 1 rural) & 2 & 2 \\
\hline CCT/Gov (rural) & 1 & 1 \\
\hline Catholic/Gov (rural) & 1 & 1 \\
\hline CCT only (rural) & (Interviews) & 1 \\
\hline Totals & 4 & 5 \\
\hline
\end{tabular}

*Sector: For workers, sector refers to the mix of providers from which focus group participants were selected. For users, sector refers to range of providers to which participants have access. 


\section{Appendix II: Matan dook treatments}

Partial list of treatments offered by one traditional healer (matan dook) in Dili (terms in Indonesian):

\begin{tabular}{|l|l|}
\hline Obat kepintaran & Memory enhancement \\
\hline Gangguan jiwa & Mental illness \\
\hline Patah tulang & Bone fracture \\
\hline Muntah darah & Vomiting (with blood) \\
\hline Buang air besar campur darah & Typhus \\
\hline Buang air kecil campur darah & $\begin{array}{l}\text { Urinary infection ("with blood when } \\
\text { urinate") }\end{array}$ \\
\hline Kencing batu & Kidney stones \\
\hline Epensit usus buntu & Appendicitis \\
\hline Perut besar/kembung & Flatulence \\
\hline Ingin kembali pada istri/suami & $\begin{array}{l}\text { Make a divorced couple get back together } \\
\text { (make someone love her/his spouse) }\end{array}$ \\
\hline Beri-beri & $?$ \\
\hline Obat untuk mendapatkan anak laki-laki & $\begin{array}{l}\text { Enable a woman to give birth to a baby } \\
\text { boy }\end{array}$ \\
\hline Obat untuk kurang darah & Anaemia \\
\hline Obat kencing manis & Diabetes \\
\hline Gangguan haid & Menstrual problem \\
\hline Kencing kuning/mata kuning & Jaundice \\
\hline $\begin{array}{l}\text { Obat untuk tidak menderita disaat } \\
\text { melahirkan }\end{array}$ & $\begin{array}{l}\text { To make a women not feel the pain when } \\
\text { she gives birth }\end{array}$ \\
\hline Gatal-gatal & Skin itches \\
\hline
\end{tabular}

